\title{
Aspects of Francophone Cameroon English Inflectional Morphology: The Case of the - s Inflection
}

\author{
Marcel Jaff Fornkwa \\ Catholic University of Cameroon, Bamenda \\ P.O. BOX 782, Bamenda, Cameroon
}

Tel: 237-75-02-92-05 E-mail: jaffmarco@yahoo.com

Received: November 1, 2012 Accepted: November 25, 2012 Published: November 26, 2012

doi:10.5296/ijele.v1i1.2766 URL: http://dx.doi.org/10.5296/ijele.v1i1.2766

\begin{abstract}
This study examines the use of the $-\mathrm{s}$ inflection by Francophone learners of English in Cameroon. Focus is on analysing the use of this inflection in the verbs and nouns that these learners use in their English essays, in order to determine the frequency of its use, the various difficulties faced by learners, and the strategies employed to overcome these difficulties; so as to determine the general trend in the use of this morpheme by these learners. The study is carried out in four schools in Yaounde: the Government Bilingual Primary School Mballa II, Lycée d'Anguissa, College Adventist and The University of Yaounde I. Data is collected from forty scripts equitably selected from these schools using random sampling. The data are analysed based on the Principles and Parameters theory in Second Language Acquisition. The general trends revealed in the findings include: French interference in the morphological parameter settings for the use of this affix, omission of the use of the affix where its use is necessary and over-generalization of the use of the affix to exceptional situations. However, some learners, especially those of Terminale and Level III, succeed in correctly setting the morphological parameter for this affix and thus use it correctly in their written English.
\end{abstract}

Keywords: inflection, affix, interference, omission, over-generalization 


\section{Background}

Cameroon is a bilingual country with English and French as the official languages since 1961 after the independence and reunification of the British and French Cameroons. These languages are used in major areas of life such as religion, education, the media, business and politics. In the area of education, French is used as the main medium of instruction in the Francophone educational sub-system, with English as a subject; while English is used as the main medium of instruction in the Anglophone sub-system, with French as a subject, in the basic and secondary educational levels.

Research on the English of Francophone Cameroonians has proven that most of them face difficulties in expressing themselves properly both in written and spoken English. It is on this basis that we have decided to carry out a morphological analysis of the written lexicon of these learners. Francophone learners of English in Cameroon range from the primary, through the secondary to the university levels.

This analysis falls within the domain of morphological analysis. According to Bauer (1983: 13), "morphology is a sub-branch of linguistics that deals with the internal structure of word-forms." The present study is therefore focused on the internal structure of the written vocabulary items of Francophone learners. This entails examining these learners' use of morphemes. A morpheme according to Radford et al (1999: 162) is "the smallest component of a word which contributes to its meaning." This includes what is known as an affix, which according to McArthur (ed.) (1992: 18) is "an element added to a word, base or roots to produce an inflected or derived form."

The present morphological analysis is thus limited to Francophone learners' use of affixes. Affixes are of two types: inflectional and derivational affixes. According to Lyons, as cited in Bauer (1983:22), "inflection produces for the stem (or stems) of a given lexeme all the word-forms of the lexeme which occur in syntactically determined environments." So, when added to words, inflectional affixes give other forms of the words. Jackson and Ze Amvela (2000) identify nine inflectional affixes and summarily present them as:

Noun $+-s,-s$, , $-s:$ possessive (singular and plural), plural

Adjective + -er, -est: comparative and superlative

Verb $+-s$, -ing,-ed, -en; third person present singular, present participle, past tense, past participle.

Derivation on the other hand is "the process of adding bound morphs to create new words of the same or different word classes" (Malmkjaer (ed.) 2004:358). Bauer (1983) presents a long but yet unlimited list of derivational affixes while classifying them into prefixes and suffixes. They include noun-forming, verb-forming, adjective-forming and adverb-forming affixes. The analysis of Francophone learners' use of affixes is done on the background of the nine inflectional affixes presented and the numerous derivational affixes presented by Bauer (1983).

This study is therefore limited only to two inflectional affixes: the verb+ -s third person 
singular and the noun+ -s plural affixes

\section{Theoretical Premise and Literature Review}

This study is based on the Principles and Parameters theory. Chomsky propounded this theory on the basis of his theory of Universal Grammar (UG); what all languages have in common. The Principles and Parameters model brings out the similarities and differences that exist between languages and shows that the acquisition of all languages follows a particular pattern. Regarding similarities, the theory "offers the postulate that there are universal principles of grammar that are, without exception, invariant across languages. The content and operation of these principles of grammar ensure the similarity of all natural languages" (Webelhuth, 1992: 8). Relating to differences, the theory postulates that "the principles of UG are supported by a set of parameters (options) provided by UG along a certain dimension from which individual grammars may select, possibly subject to relative conditions of accessibility and markedness" (ibid: 8).

\subsection{Principles}

As stated above, there are universal principles of grammar that are, without exception, invariant across all languages. This can be justified by the fact that despite the many variations in the forms and structures of the various human languages, they are all used in various societies for the same ends. This universality in function must therefore have some linguistic evidence in all languages, hence the existence of the universal principles of grammar. It is a universal principle of grammar that words in all languages are classified according to grammatical categories such as nouns, verbs, adjectives, adverbs, etc. Furthermore, in all languages, these words play different functions in sentences. They can be subject, verb, object, complement or adverbial.

These are just few examples of the universal principles of language. The existence of these universal principles is accounted for, from the Chomskyian perspective, by the innate knowledge that the human species is genetically endowed with. Ellis (1985: 191) quotes Cook (1985) who explains this by stating that "language properties inherent in the human mind make up 'Universal Grammar' which consists not of particular rules of a particular language, but a set of general principles that apply to all languages." These inherent language properties are already present in all children's mind when they come to the task of acquiring any language, in what Chomsky refers to as the 'language faculty', otherwise known as the Language Acquisition Device (LAD). This is "a component of the human mind physically represented in the brain and is part of the biological endowment of the species" (Chomsky, 2002: 1).

Chomsky's explanation for the innateness of UG is that without a set of innate principles, it would not be possible for a child to learn the grammar of his mother tongue. This is because the data available from the input are insufficient to enable the child to discover certain rules. (Ellis, 1985: 192)

Felix (1984) concedes with this claim and advances three reasons to justify it: 
1. Some structures are so rare and marginal; therefore the child will hardly get any such data from the environment that will enhance acquisition.

2. There is hardly or never any negative feedback (negative evidence) from the environment. So it will be difficult for learners to correct their errors.

3. The rules of the grammar of human languages are so abstract and complicated for a learner to acquire without any natural predisposition.

These justifications enlighten the fact that a child cannot succeed in learning a target language by depending uniquely on the input from the environment. This is referred to in language acquisition as the 'poverty of the stimulus.' The child therefore makes use of UG which is innate and input from the society which serves as triggering data in order to learn any target language.

\subsection{Parameters}

Despite the fact that there are general principles that are invariant across all languages, there are certain properties of language that are language-specific. This is what explains the variation between different languages. There therefore exist certain parameters under which languages vary. According to Haegeman (1991: 14), the mastery of these language-specific properties requires very little learning, just as is the case with the universal principles. This is because "for those principles that are parametrized, the available options are given by UG. Attaining linguistic knowledge consists in fixing the parameters." Ellis (1985: 193) explains this concept by stipulating that UG "constrains the form which the grammars of individual languages can take" not by "providing the child with ready-made rules" but by providing "parameters which must then be fixed according to the particular input data that the child obtains." For acquisition to take place, the child therefore needs input from the environment in order to set the parameters of the target language, while depending on the innate principles of grammar that $\mathrm{s} /$ he is naturally endowed with.

The universal principles of grammar that we saw in the previous section all provide parameters under which languages vary. We saw that in all languages, words are classified into categories and that they play different roles in sentences. However, the way these elements are ordered in sentences differs across languages. The word-order parameter therefore accounts for cross linguistic variation as concerns the ordering of words in sentences. This can be observed in the French and English sentences below:

She is eating it.

$$
\text { S } \quad \mathrm{V} \quad \mathrm{O}
$$

Elle la mange.

\section{$\mathrm{S} \quad \mathrm{O} \quad \mathrm{V}$}

We can see that although the sentences above have the same elements, they are ordered differently in the two languages. In English, a pronoun functioning as object comes after the verb, while in French; it comes before the verb in sentences. 
Besides, although the manipulation of words to indicate number or tense is a universal principle, the actual processes differ across languages. This can be termed the inflection parameter. For example, the affixes that are added to verbs to indicate tense differ between French and English. This therefore constitutes the base for this study.

\subsection{Principles and Parameters, and Second Language Acquisition (SLA)}

Chomsky propounded the Principles and Parameters theory to account for L1 acquisition. It has however been proven that the theory also accounts for SLA.

Saville-Troike (2006) identifies the relevance of the Principles and Parameters theory in SLA in a three state process. During what she terms the initial state in SLA, "learners already have knowledge of L1 at the point where SLA begins; they already have made all the parametric choices that are appropriate for that L1, guided by UG. Some L1 knowledge is clearly transferred to L2, depending on the relationship of L1 and L2 and other factors" (ibid: 50). When we talk of transfer here, two possibilities present themselves: there can be positive transfer from L1 to L2 when the L1 and L2 parameter settings for the same principle are the same, as well as there can be negative transfer or interference, when the L1 and L2 parameter settings are different. This interference therefore constitutes one of the major preoccupations of this study because it poses as a difficulty to accurate L2 acquisition. Thus, in our analysis of the morphological difficulties of Francophone learners of English, we are looking for difficulties that come up due to negative transfer or interference.

The second state in which the theory relates to SLA is in the nature and development of interlanguage. Considering interlanguage from a Principles and Parameters perspective as the "immediate states of L2 development (IL1, IL2, IL3, etc)," Saville-Troike (2006:51) states that "the process of interlanguage development is in large, one of resetting parameters on the basis of input in the new language." The acquisition of an L2 therefore demands that learners reset the parameters of their L1 to suit the principles of the L2, depending on the input they receive from the environment. This change or resetting of parameters imposes itself in situations where the L2 input learners receive does not match with the L1 settings they have.

Three related hypotheses that account for the effect of universals in interlanguage development have been advanced:

1. Like other natural languages, interlanguage is subject to the constraints imposed by linguistic universals.

2. Implicational universals can be used to predict the order in which properties of the L2 appear in interlanguage.

3. L2 learners learn unmarked (or less marked) properties before marked (or more marked) properties of the target language. (Ellis, 1985).

In our analysis of the development of the interlanguage of Francophone learners of English in Cameroon, we are therefore investigating the difficulties that these learners face in learning marked properties related to the morphology of English; in other words, the difficulties that these learners face in resetting the marked properties of the morphology of English, which are 
not accounted for by the parametric choices that they had earlier made.

The third state is the final state, during which learners attain an acceptable level of competence in the target language. This is the state in which learners' interlanguage reaches an approximate level of the L2. According to Saville-Troike (2006: 52), "L2 learners' attainment of the final state varies greatly among learners" and can be accounted for by the following possibilities:

1. All learners may not have the same degree of access to UG.

2. Different relationships between various L1s and L2s may result in differential transfer or interference.

3. Some learners receive more qualitatively different L2 inputs from others.

4. Some learners may be more perceptive than others of mismatches between L2 input and existing L1 parameter settings.

5. Different degrees of specification for lexical features may be achieved by different learners.

Taking into consideration these possibilities, we are examining the difficulties that the Francophone learners of English of our study encounter in their process to attain the final state in the acquisition of the target language.

We can therefore summarily situate this study within the scope of the Principles and Parameters framework by stating that we are basing our analysis on Chomsky's theory of Principles and Parameters to examine how negative transfer or interference, parameter resetting of marked properties and the different possibilities that learners are exposed to, pose difficulties to the acquisition of accurate properties of English morphology by Francophone learners of English in Cameroon.

\subsection{Previous Literature}

While presenting the various categories of words, Parrot (2000) advances some possible difficulties they may pose to learners. We are more interested here in the difficulties related to the morphology of words. To that respect, Parrot (ibid) postulates that in relation to nouns, learners sometimes face difficulties with the pluralisation of nouns; using plural nouns as though they were singular, choosing the wrong plural form, and using plural nouns as though they were uncountable.

In relation to verbs, learners face difficulties in inflecting verbs to indicate the various verb tenses. This leads them into mixing up tenses, for example, using the present perfect for the past simple and vice versa. This problem is more serious with irregular verbs.

Previous research on Francophone Cameroonian learners' use of English has revealed that they face similar difficulties with the morphology of English nouns and verbs. Ntankeu (1989) analyses English essays of Troisième students of C. E. S Sa'a and comes out with findings showing that these students over-generalize the use of the $-e d$ morpheme as a past tense 
marker to irregular verbs and some of them omit the $-s$ morpheme to indicate the third person singular in the present tense.

Comparing the English language performance between Lycée de Mballa II and Lycée Bilingue d'Application in Yaounde, Njenga (1994) reveals that students from both institutions face difficulties in inflecting verbs to indicate the various verb tenses; that is, ignoring or misusing the four inflectional suffixes that indicate tense $(-s,-e d$, $-e n$, and $-i n g)$. These students also in some cases ignore the use of the $-s$ morpheme to indicate plurality in nouns and also over generalize the use of the $-s$ morpheme to indicate plurality with irregular nouns. Besides, these students also falsely use the $-s$ morpheme to mark plurality in adjectives.

Neba (2002) observes the manipulation of irregular noun and verb related inflectional morphology in English by students of Form One. Through observations, interviews and written tests, she uses the error analytical method to come out with findings that these students tend to over generalise the use of the -ed morpheme to form the past tense of irregular verbs. There is also the redundant use of the past tense and the addition of the $-S$ morpheme in the plural forms of irregular nouns, instead of an internal change. In general, the errors identified stem from the wrong verb, noun and adjective inflectional morphology. Some inflectional affixes are used when they are not supposed to be. This mostly involves the formation of the past and plural forms of irregular verbs and nouns respectively.

Kameni (2004) in an investigation of the problems encountered in the use of English by second year engineering students of Ecole Nationale Superieure Polytechnique, uses questionnaires and tests to come out with the findings revealing that these students face problems mainly with the morphology of verbs. A greater percentage of them face difficulties in using the third person present singular $-s$, the -ing form, the past participle forms and the past simple forms.

Etame (2005) examines the way first year Francophone science student-teachers of E. N. S. Yaounde use English grammar in general and parts of speech in particular. His findings reveal that these students use wrong inflections with adjectives and adverbs, omit or over generalize the $-s$, ing, -en, and -ed endings of verbs, ignore the past participle of verbs, over generalize the use of the $-s$ to indicate plural forms of nouns and omit the $-s$ morpheme in plural forms

From the above reviews, it is evident that the bulk of research on the English of Francophone learners of English has been focusing only on single classes in only single schools. By choosing different levels in different schools, we will be able to study the evolution of the English morphology of Francophone learners as they advance in education.

Besides, in this study, we are examining the extent to which our population of study faces these morphological difficulties and others that will be identified in the course of our analysis. We are also examining the various strategies adopted by the learners to tackle these difficulties.

Ellis (1997: 34) identifies the various strategies employed by learners to develop their interlanguage. These strategies that include omission, overgeneralization and transfer are reflected in the different kind of errors produced by the learners in the course of learning. 
Littlewood (1984) gives a detailed description of how second language learners use these strategies in SLA. According to him, "learners' errors need not be seen as signs of failure. On the contrary, they are the clearest evidence for the learners' developing systems and can offer us insights into how they process the data of the language" (ibid: 22).

According to Littlewood, overgeneralization errors occur because learners have either over-generalized a rule to cover an exceptional item within a given category, or because learners have over-generalized a rule to cover an item that is not within the category covered by the rule. In both cases, learners must therefore need to learn an exception to the general rule or construct a new category and rule respectively. For example:

A learner of English (as a first or second language) has learnt a rule for forming plurals. This lets him predict that a noun can be made plural by adding - - . However, when he says We saw two mouses, he has over-generalized the rule, since mouse is one of the exceptions to it. In a similar way, until he learns that come and go lie outside the scope of the general rule for forming the past tense, he is likely to produce over-generalized forms such as comed and goed. (ibid: 24).

In other cases, second language learners turn to transfer their previous knowledge of language (including the first language) to the new tasks. In situations where the languages have similar parameter settings, the hypotheses will be confirmed. But when the parameter settings are different in the two languages, transfer will lead to errors in the second language due to the interference of $\mathrm{L} 1$ rules in the $\mathrm{L} 2$.

Another learning strategy used by L2 learners is omission. This occurs due to some elaborative simplification of items. According to Littlewood (1984: 28), "the omission of inflections and other morphemes seems to be due more to limitations in capacity than to the construction of rules." This is a kind of redundancy reduction because learners turn to eliminate smaller items and concentrate on the items that convey the intended meaning. This simplifies production "but may, of course, make comprehension difficult or even impossible" (ibid). For example in: Daddy want chair, the verb inflection and the article have been omitted.

Saville-Troike (ibid: 174-176) also presents what exactly the L2 leaner comes to know and how the learner acquires L2 knowledge. According to him, what exactly the learner comes to know includes; a system of knowledge about a second language, patterns of recurrent elements that comprise components of L2-specific knowledge: vocabulary, morphology, phonology, syntax, and discourse, how to encode particular concepts in the L2, pragmatic competence, means of using the L2 in communicative activities and communicative competence. The leaner acquires this L2 knowledge by using his innate language acquisition capacity, applying his prior knowledge of his L1 as well as prior social experience, interaction, restructuring of the L2 knowledge system, mapping of relationships of associations and by automatization.

In the present study, focus is on examining the various strategies used by learners in the 
acquisition and learning of the morphological properties of English, and how their productions reflect the rules which they have internalized; that is, their underlying competence in the second language.

\section{Data}

Data for this study is derived from 40 English essay scripts collected from Francophone learners of English at various levels of education: primary, first cycle of secondary, second cycle of secondary and the university. Hence, 10 scripts are randomly and respectively collected from learners in Cours Moyen II at Government Bilingual Primary School Mballa II, Troisième at Lycée d'Aguissa, Terminale at Collège Adventiste Yaounde and Level III at the University of Yaounde I. ${ }^{1}$ We first of all read through the scripts, while identifying all the instances of the use of the two inflectional affixes. We then proceeded by entering them into databases. Another reading of the scripts was done with focus on identifying all the problematic instances of the use of affixes. They were in turn entered into databases. Another reading of the scripts was done with focus on identifying the various avoidance strategies used by learners to overcome their morphological difficulties. The data collected on this was also entered into data bases. We therefore have three main data bases; one for the correct use of affixes, one for problems involving the use of affixes, and another for avoidance strategies involving the use of affixes. It is the data in these data bases that we proceed to analyse.

Data analysis is done at various stages. In the first stage we study the information on the databases and come up with frequency tables showing the occurrence of the correct use of the two inflectional affixes. We then proceed by focusing on the difficulties faced by the learners in the inflection of words and the various strategies employed by learners to overcome these difficulties. We asses the productivity in the use of these strategies and also come-up with tables showing the frequency of their use. These tables show how the frequencies vary according to the various levels involved in the study.

\section{Findings}

The analysis of the findings focuses on the learners' use of the two inflectional affixes: the verb+-s and the noun+-s. The inflectional properties relating to these affixes that feature in learners' scripts are examined. The frequency of their occurrence and the productivity in their use are analysed and compared to show how they vary first within learners of the same level, and then with learners across the various levels.

As earlier mentioned, our analysis is limited only to one verb inflection and one noun inflection. The table below presents a general view of the correct use of these two affixes across the various levels. The table shows the frequency of the use of the two inflections in each of the 10 scripts selected at the various levels, while providing the total frequency of the use of these inflections at the various proficiency levels.

\footnotetext{
${ }^{1}$ Cours Moyen II, Troisième and Terminale are respectively final year classes of the primary, first cycle secondary and second cycle secondary levels of the Francophone system of education in Cameroon.
} 
Table 1. Correct use of inflectional affixes

\begin{tabular}{|l|l|l|l|l|l|l|l|l|l|l|l|l|}
\hline \multicolumn{2}{|l}{ Script no. } & 1 & 2 & 3 & 4 & 5 & 6 & 7 & 8 & 9 & 10 & Total \\
\hline \multirow{5}{*}{ Verbs $+-s$} & CM2 & 1 & 1 & 0 & 0 & 1 & 0 & 0 & 0 & 0 & 0 & 3 \\
\cline { 2 - 13 } & Troisième & 1 & 0 & 0 & 0 & 1 & 0 & 0 & 1 & 0 & 0 & 3 \\
\cline { 2 - 13 } & Terminale & 1 & 3 & 1 & 1 & 0 & 0 & 0 & 1 & 3 & 0 & 10 \\
\cline { 2 - 13 } & Level III & 5 & 2 & 3 & 3 & 0 & 1 & 0 & 5 & 1 & 2 & 22 \\
\hline \multirow{4}{*}{ Noun+-S } & CM2 & 2 & 2 & 1 & 1 & 3 & 2 & 0 & 0 & 1 & 0 & 12 \\
\cline { 2 - 12 } & Troisième & 1 & 5 & 0 & 0 & 3 & 0 & 3 & 2 & 4 & 2 & 20 \\
\cline { 2 - 12 } & Terminale & 5 & 5 & 5 & 14 & 9 & 7 & 12 & 14 & 15 & 12 & 98 \\
\cline { 2 - 11 } & Level III & 15 & 12 & 11 & 12 & 3 & 14 & 8 & 10 & 1 & 13 & 99 \\
\hline
\end{tabular}

The table above shows that the frequency of the correct use of the two inflectional affixes rises as we move from the primary, through the secondary to the university levels. These frequencies fall below what was expected, given that the essay tasks given to the learners required an extensive use of the inflections above. It is therefore certain that the learners did not use the inflections in all the situations in which their use was required. We are going to closely examine the use of these two inflections one after the other.

\subsection{The Use of Verb+-s}

Given that the frequency of the correct use of this inflection was not as high as expected, we decided to determine the various strategies employed by learners in situations in which the use of the $-\mathrm{s}$ inflection with verbs was required. A close examination of learners' scripts revealed two of such strategies: simplification by omission and the use of alternative forms. These are going to be analysed one after the other.

\subsubsection{Simplification by Omission}

An examination of learners' scripts revealed that in some situations in which learners were required to use the $-\mathrm{s}$ inflection with verbs, they simply omitted it, making use of the infinitive word-form. The table below presents the frequency of this phenomenon in the selected scripts at the various levels.

Table 2. Omission of $-\mathrm{s}$ in verbs

\begin{tabular}{|l|l|l|l|l|l|l|l|l|l|l|l|l|}
\hline \multicolumn{2}{|l|}{ Script no. } & 1 & 2 & 3 & 4 & 5 & 6 & 7 & 8 & 9 & 10 & Total \\
\hline \multirow{4}{*}{ Level } & CM2 & 4 & 5 & 4 & 5 & 3 & 4 & 3 & 5 & 4 & 3 & 40 \\
\cline { 2 - 14 } & Troisième & 2 & 2 & 3 & 1 & 3 & 2 & 2 & 4 & 5 & 3 & 27 \\
\cline { 2 - 13 } & Terminale & 1 & 0 & 1 & 1 & 3 & 1 & 3 & 1 & 2 & 3 & 18 \\
\cline { 2 - 12 } & Level III & 1 & 3 & 2 & 1 & 0 & 1 & 1 & 1 & 1 & 2 & 13 \\
\hline
\end{tabular}

As can be seen from the table above, the frequency of the omission of $-\mathrm{s}$ in verbs reduces as we move from the primary, through the secondary to the university levels. At CM2 and Troisième, the phenomenon is highly recurrent in all 10 scripts, yielding the total frequencies of 40 and 27 respectively; which are far above the total frequencies of the correct use of the $-\mathrm{s}$ inflection in verbs at these levels (see Table 1). At Terminale and Level III, one learner 
each succeeds to completely avoid this omission and more than half of the rest omit $-\mathrm{s}$ in verbs only once in their scripts. This shows a great improvement in the mastery and use of the $-\mathrm{s}$ verb inflection as compared to the lower levels. However, we note that right at Level III in the university; a majority of Francophone learners still continue to omit the -s verb inflection where its use is required. This is unfortunately not a successful strategy as the result of such omission is a deviant structure. Some examples identified in learners' scripts include:

1. My father *like Achu and yellow soup.

2. He *work in the bush.

\subsubsection{Use of Other Verb-Forms}

It was also observed that in some situations in which learners were required to use the $-s$ verb inflection, they employed an avoidance strategy by using an alternative form. This was mainly done by using the -ing form, the future tense, the -ed inflection or the auxiliary can plus the infinitive. The use of these forms is going to be examined according to the various levels.

\section{A. Alternative forms at CM2}

The various other verb-forms used in place of the verb-s inflection that were identified at this level included the -ing verb-form and the future tense. The table below presents the frequency of these forms in the 10 scripts selected at this level.

Table 3. Frequency of alternative forms at CM2

\begin{tabular}{|l|l|l|l|l|l|l|l|l|l|l|l|}
\hline Script no. & 1 & 2 & 3 & 4 & 5 & 6 & 7 & 8 & 9 & 10 & Total \\
\hline -ing form & 0 & 0 & 0 & 1 & 1 & 0 & 2 & 1 & 0 & 0 & 5 \\
\hline Future tense & 0 & 0 & 0 & 2 & 0 & 0 & 0 & 0 & 0 & 0 & 2 \\
\hline
\end{tabular}

In some situations where the use of the $-\mathrm{s}$ inflection with verbs was required, learners avoided it and used the -ing verb form. Examples include:

3. My father is not caring for us.

4. My father is a smooking man.

This strategy was fairly productive at this level as the total frequency of such structures on the 10 scripts selected was 5 . This can be considered as a successful strategy as the resultant form is not a deviant structure.

In other situations that required the use of the - s inflection with verbs, learners avoided it by using the future tense. Examples include:

5. When I ask something from him, he will give.

This strategy was not very productive as its total frequency was only 2 in the 10 scripts selected at this level. It is however a successful strategy as the resultant structure is not a deviant form. 
B. Alternative forms at Troisième

At this level the only alternative form used by learners in place of the -s verb inflection was the past tense inflection -ed. The frequency of its use is presented on the table below.

Table 4. Use of -ed in place of - s with verbs

\begin{tabular}{|l|l|l|l|l|l|l|l|l|l|l|l|}
\hline Script no. & 1 & 2 & 3 & 4 & 5 & 6 & 7 & 8 & 9 & 10 & Total \\
\hline Use of -ed & 1 & 0 & 1 & 0 & 2 & 0 & 1 & 1 & 0 & 1 & 7 \\
\hline
\end{tabular}

The table above shows that in 6 of the 10 scripts, learners used the -ed verb inflection in contexts where the $-\mathrm{s}$ inflection was required at least once yielding a total frequency of 7 . Despite the productivity of this strategy, it is unfortunately not a successful one because the resultant word-form is deviant in context. Examples include:

6. Religion *prepared the Christian to enter in communion with Christ.

7. Religion is important for our life because he $*$ determined...

We note here that the other successful strategies (the -ing form and the future tense) identified at CM2 completely disappear at Troisième contrary to expectations. We instead have here a high frequency of a deviant form. This can be accounted for by the fact that at this level, learners have been introduced to many verb inflections and they do not yet master their use very well. So, they end up in confusion, using one inflection when another is required.

\section{Alternative forms at Terminale}

The other forms used in place of the $-\mathrm{s}$ inflection at this level include the -ing verb form, the future form and the -ed form. The table below presents the frequency of these forms on learners' scripts.

Table 5. Frequency of alternative forms at Terminale

\begin{tabular}{|l|l|l|l|l|l|l|l|l|l|l|l|}
\hline Script no. & 1 & 2 & 3 & 4 & 5 & 6 & 7 & 8 & 9 & 10 & Total \\
\hline -ing form & 0 & 0 & 1 & 0 & 0 & 0 & 0 & 1 & 0 & 0 & 2 \\
\hline Future form & 0 & 0 & 0 & 0 & 1 & 0 & 0 & 0 & 0 & 0 & 1 \\
\hline -ed form & 1 & 0 & 0 & 0 & 1 & 0 & 0 & 0 & 0 & 0 & 2 \\
\hline
\end{tabular}

The alternative forms used at this level in the place of the $-\mathrm{s}$ verb inflection were not very productive given the frequencies on the table above. We however note the resurfacing of the successful use of the -ing and the future forms and the reduction in the frequency of the use of the deviant -ed verb form at this level. This shows an improvement in learners' mastery as their proficiency level increases.

\section{Alternative forms at Level III}

The alternative forms used in place of the $-\mathrm{s}$ verb inflection identified at this level included the use of can plus the infinitive and the use of the -ed form. The table below shows the frequency of these forms. 
Table 6. Frequency of alternative forms at Level III

\begin{tabular}{|l|l|l|l|l|l|l|l|l|l|l|l|}
\hline Script no. & 1 & 2 & 3 & 4 & 5 & 6 & 7 & 8 & 9 & 10 & Total \\
\hline Can + inf. & 3 & 0 & 2 & 2 & 0 & 3 & 0 & 0 & 0 & 0 & 10 \\
\hline -ed form & 1 & 0 & 0 & 0 & 0 & 0 & 0 & 0 & 1 & 0 & 2 \\
\hline
\end{tabular}

It was observed that in some situations in which the use of the $-\mathrm{s}$ verb inflection was required; learners at this level successfully avoided it by using the auxiliary can plus the infinitive of the verb. Examples include:

8. Sociology can explain...

9. Any development project which wants to take place in an area can take into consideration local mentality.

This strategy was highly productive given that it was identified on 4 of the 10 scripts with a total frequency of 10. Besides, it was a successful strategy given that it did not result to a deviant structure.

In other situations requiring the use of the $-\mathrm{s}$ inflection, learners at this level still made use of the -ed verb-form as was in the case at the previous levels. However, the frequency of this deviant use drops at this level to only 2 ; showing an improvement in learners' mastery as their proficiency level increases.

We observe here that from a general perspective, the avoidance strategy with the highest productivity used by learners of all the proficiency levels is simplification by omission, which is recurrent on above $80 \%$ of the scripts at all levels. The use of other alternative forms is not very productive. The use of the -ing form has the highest frequency at CM2 and Terminale. The -ed form is very recurrent at Troisième but drops at Terminale and Level III as learners' mastery improves. The can + infinitive form is highly productive at Level III.

The inability of these learners to use the $-\mathrm{s}$ verb inflection in all the situations in which it is required surely stems from the fact that the principles of inflecting verbs in French in the present tense are quite different from those in English. At the third person singular, for example, there is no use of the $-\mathrm{s}$ in French, unlike is the case in English. Thus, learners obviously face difficulties in resetting their verb inflectional parameters to suit the principles of English grammar. That is why a very large majority of them simply omit the use of the inflection while others use alternative forms and others use forms that are completely wrong in the contexts.

\subsection{The Use of the Plural Noun Morpheme $-\mathrm{S}$}

Plurality with most English nouns is marked by adding an $-\mathrm{s}$ to the singular noun-forms. The statistics on Table 1 show that the total frequency of the correct use of this affix ranges from 12 at CM2, to 29 at Troisième, 98 at Terminale and 99 at Level III. We observe an increase in the frequency as we move from the primary through the secondary to the university levels.

It is important to comment here that the slightly high frequency of the correct use of the plural morpheme is accounted for by the positive transfer of parameter settings from French 
to English. Just as is the case in English, plurality with most nouns in French is marked by adding an $-\mathrm{s}$ to the singular noun-forms. So learners easily transfer this principle to English and correctly use it to mark plurality with English nouns.

However, despite the fact that the parameter settings for the use of $-\mathrm{s}$ to mark plurality with most nouns are similar in French and English, some Francophone learners still face some difficulties in using this morpheme with English nouns in some situations where necessary. They therefore resort to the use of other strategies to overcome these difficulties. The strategies identified in the scripts analyzed include mainly simplification by omission and overgeneralization. The use of these strategies is analyzed below.

\subsubsection{Simplification by Omission}

An examination of learners' scripts revealed that in some situations in which they were required to use the $-\mathrm{s}$ inflection to mark plurality with nouns, they simply omitted it, making use of the base forms of the nouns. The table below presents the frequency of this phenomenon in the scripts at the various levels.

Table 7. The omission of $-\mathrm{s}$ in plural nouns

\begin{tabular}{|l|l|l|l|l|l|l|l|l|l|l|l|}
\hline Script no. & 1 & 2 & 3 & 4 & 5 & 6 & 7 & 8 & 9 & 10 & Total \\
\hline CM2 & 4 & 1 & 2 & 1 & 0 & 1 & 2 & 0 & 3 & 4 & 17 \\
\hline Troisième & 4 & 6 & 5 & 6 & 0 & 5 & 4 & 5 & 2 & 4 & 41 \\
\hline Terminale & 0 & 4 & 4 & 2 & 4 & 4 & 2 & 2 & 0 & 3 & 25 \\
\hline Level III & 2 & 2 & 5 & 4 & 3 & 0 & 0 & 2 & 5 & 0 & 23 \\
\hline
\end{tabular}

The statistics on the table above show that the omission of $-\mathrm{s}$ in plural nouns was recurrent in almost all the scripts selected at the various levels. This results in very high frequencies of this omission especially at CM2 and Troisième where the total frequency of the omission of the morpheme (17 and 41 respectively) was more than that of its correct use (12 and 20 respectively). The frequency of the omission dropped far below that of its correct use at Terminale and Level III, showing an improvement in the mastery of the use of the morpheme as learners advance in education. Some examples of this omission are presented below.

$$
\begin{aligned}
& \text { 10. ...5o *kilometre... } \\
& \text { 11. ...many *body... } \\
& \text { 12. ... most high *personality... } \\
& \text { 13. ...many of our *language... }
\end{aligned}
$$

It is necessary to comment here that the omission of $-\mathrm{s}$ in word final position, as in plural noun-forms, is a common feature in Francophone English speech, as indicated by Kouega (2009). This is due to the fact that in French, $-s$ in word final positions remains silent during speech though represented orthographically. So, Francophone learners of English tend to transfer this not only in to their English speech but also to their written English. This results in the interference of French parameter settings with the principles of English morphology. Given the high frequency of this phenomenon, this should be considered as an integral part of 
the development of the interlanguage of Francophone learners of English.

\subsubsection{Overgeneralization}

A close examination of learners' scripts also revealed that learners in some situations tend to over-generalize the use of the $-\mathrm{s}$ morph to mark plurality with nouns. This involved mainly the addition of $-\mathrm{s}$ to nouns that are generally not pluralized in English except in particular contexts. The table below presents the frequency of this phenomenon on the scripts at the various levels.

Table 8. Overgeneralization of the use of $-S$

\begin{tabular}{|l|l|l|l|l|l|l|l|l|l|l|l|}
\hline Script no. & 1 & 2 & 3 & 4 & 5 & 6 & 7 & 8 & 9 & 10 & Total \\
\hline CM2 & 0 & 2 & 0 & 0 & 0 & 0 & 0 & 0 & 0 & 0 & 2 \\
\hline Troisième & 0 & 1 & 0 & 0 & 0 & 0 & 1 & 0 & 0 & 0 & 3 \\
\hline Terminale & 1 & 1 & 0 & 1 & 0 & 1 & 0 & 0 & 0 & 2 & 3 \\
\hline Level III & 0 & 0 & 0 & 0 & 1 & 1 & 0 & 0 & 1 & 0 & 2 \\
\hline
\end{tabular}

The statistics on the table above show that the overgeneralization of the use of $-\mathrm{s}$ to nouns that are generally not pluralized was not very much recurrent in most scripts at all the levels. This is due to the fact that such nouns are not generally many, resulting in the low total frequencies that we observe above. The total frequency of this phenomenon starts from 2 at $\mathrm{CM} 2$, rises to 3 at Troisième and Terminale respectively and drops to 2 at Level III. The rise at the secondary levels can be accounted for by the fact that at this level, learners are exposed to more words whose morphology they do not yet master. At the university level, their mastery of word morphology has improved and this accounts for the drop at Level III. Some examples of this overgeneralization are presented below.

14. We bought * foods and drinks.

15. ...*humilities...

16. ... due to lack of *works...

17. ...*informations...

Given the difficulty faced by second language learners to set new parameters that suit with such exceptional rules, overgeneralization problems like the one above are therefore expected to be a common feature in the development of the interlanguage of Francophone learners of English.

\section{Discussion}

The findings are discussed in relation to the various issues highlighted from the analyses, previous literature, the Principles and Parameters theory and learners' background.

\subsection{Simplification by Omission}

The omission of morphemes in situations where their use is necessary was identified as a recurrent phenomenon in most learners' English essays. This involved mainly the omission of 
-s with verbs and nouns. Such omissions are a clear manifestation of learners' difficulty to master the morphology of English words. They therefore resort to such omissions as a simplification strategy. According to Littlewood (1984), learners resort to omission because they turn to eliminate smaller items and concentrate on items that convey the intended meaning. This therefore results in structures such as:

He *work...instead of He works...

Furthermore, some of these omissions are a result of the negative transfer of French parameter settings into learners' written English. The results show that a majority of Francophone learners omit the $-\mathrm{s}$ inflection with verbs at the third person singular present tense. We consider this as the negative transfer of French parameter settings, since verbs in similar contexts in French do not take the $-\mathrm{s}$ inflection. Besides, in French, when the morphemic representation of the plural morpheme is $-\mathrm{s}$, its allomorphic realisation is $/ \varnothing /$. . So the $-\mathrm{s}$ at the end is generally silent. What helps the learner to mark plurality is the article. For example:

Le garçon - Les garçons

Most Francophone learners tend to transfer this allomorphic realisation of $-\mathrm{s}$ from French to English. So they generally do not pronounce the $-\mathrm{s}$ at the end of words and finally end up not writing it. This leads them into a problem in marking plurality in English especially as most English articles can not help them to know whether the noun is plural or singular. For example:

$\underline{\text { The }}$ boy $-\underline{\text { The boys }}$

This therefore accounts for the omission of $-\mathrm{s}$ in plural nouns by some learners in some contexts.

Previous researchers such as Njenga (1994), Neba (2002) and Etame (2005) consider such omissions as errors resulting from learners' poor mastery of grammatical rules. We do not consider them as such. These learners are still in the process of interlanguage development and since these omissions are recurrent, they should be considered as a feature of their interlanguage. This therefore means that if we are reading anything written by Francophone learners of English, we should expect to see instances of the omission of some morphemes. We therefore converge here with Ellis (1997) who considers such omissions as one of the strategies employed by learners to develop their interlanguage. We thus observe here that the omission of morphemes is bound to be a very frequent phenomenon in Francophone learners' written English. So, such omissions should be seen as a feature of their interlanguage development.

\subsection{The Use of Alternative Forms}

As seen in the findings, learners avoided the use of some affixes and used alternative forms in contexts where the affixes were required. This involved mainly the $-\mathrm{s}$ verb inflection. In some situations, the alternative forms used were successful as they correctly fitted in the context. For example: 
Sociology can explain...instead of Sociology explains...

In other situations the alternative forms used were not successful as they resulted in deviant structures. For example:

My father worked... instead of My father works...

The use of alternative forms stems from the fact that learners have not yet adequately set parameters for the correct use of the affixes in question. So they resort to the use of what they already know irrespective of whether this can be successful or not.

The use of both correct and incorrect morphological forms in the place of others should therefore be considered as an integral part of Francophone English morphology, given the fact that learners find it difficult to use all the affixes correctly in all the situations requiring their use.

\subsection{Over-generalisation}

In some situations, learners over-generalised a rule they learnt to some items exceptionally not covered by the rule. This phenomenon was identified mainly with the use of the $-\mathrm{s}$ inflection with nouns such as food, information and research that are generally not pluralized except in special contexts. This resulted in some deviant forms. According to Littlewood (1984), overgeneralization errors occur because learners have either over-generalized a rule to cover an exceptional item within a given category, or because learners have over-generalized a rule to cover an item that is not within the category covered by the rule. We therefore observe that the overgeneralization problem identified above is accounted for by the former reason. Learners tend to pluralize nouns that are exceptionally not generally pluralized. To solve such problems, learners must therefore need to learn an exception to the general rule and create a new category and rule.

Ntankeu (1989) and Nanga (2004) consider over-generalisation as one of the major causes of errors in the English of secondary school learners. This should however not be a major cause of concern, because these learners are still developing their interlanguage. So, they have not yet attained that stage of learning and applying exceptions to general rules. Given the difficulty faced by second language learners to set new parameters that suit with such exceptional rules, overgeneralizations like the one above should therefore not be considered as errors as such. They are therefore expected to be a common feature in the development of the interlanguage of Francophone learners of English.

\section{Conclusion}

The major focus in this work has been to examine the various difficulties faced by Francophone learners of English in Cameroon with the inflectional morphology of English words. After analysing their use of the $-\mathrm{s}$ suffix with verbs and nouns, it was discovered that these learners do not always use these inflections correctly where need arises because they fail to reset their language parameters to suit the principles of the correct use of these affixes in English. As such they end up omitting these affixes where necessary, using other forms or over-generalizing their use to exceptional cases. The rise in the frequency of the correct use 
of these affixes from the primary to the university levels and the drop of the frequency of the use of deviant forms from the primary to the university levels show the developmental trends in the acquisition and use of these inflectional affixes by Francophone learners of English.

Given the findings of this study, it would be necessary to examine how these learners of English acquire and use the other inflectional affixes so as to determine whether one will arrive at similar findings or something else.

\section{References}

Bauer, L. (1983). English word-formation. Cambridge: Cambridge University Press. http://dx.doi.org/10.1017/CBO9781139165846

Chomsky, N. (2002). On Nature and Language. Ed. by L. Rizzi \& A. Belleti. Cambridge: Cambridge University Press. http://dx.doi.org/10.1017/CBO9780511613876

Cook, V. (1988). Chomsky's Universal Grammar. Oxford: Oxford University Press.

Ellis, R. (1985). Understanding Second Language Acquisition. Oxford: Oxford University Press.

Ellis, R. (1997). Second Language Acquisition. Oxford: Oxford University Press.

Etame, E. (2005). Some grammatical problems in the essays of Francophone students of the science classes in E. N. S Yaounde. DIPES II_dissertation, E N S Yaounde.

Felix, S. (1984). Maturitional aspects of universal grammar. In Allan Davies, Clive Cripper, \& Anthony P. R. Howatt (Eds.), Interlanguage (pp. 133-161). Edinburgh: Edinburgh University Press.

Jackson, H., \& E. Zé Amvela. (2000). Words Meaning and Vocabulary: An introduction to modern English lexicology. London: Continuum.

Kameni, T. (2004). The use of English by second year engineering students of Ecole Nationale Superieure Polytechnique (ENSP) Yaounde: An appraisal of problems encountered. Master's dissertation, The University of Yaounde I.

Littlewood, T. (1984). Foreign and Second Language Learning: Language acquisition research and its implication for the classroom. Cambridge, Cambridge University Press.

Lyons, J. (1981). Language and Linguistics. Cambride: Cambridge Unversity Press.

Malmkjaer, K. (Ed.) (2004). The Linguistic Encyclopaedia (2 ${ }^{\text {nd }}$ ed.). London: Routledge.

Neba, M. (2002). The manipulation of irregular noun and verb related inflectional morphology in English: A case study of form one students of Government Bilingual High School Bonaberi Douala. Master's dissertation, The University of Yaounde I.

Njenga, N. (1994). A comparative study of English language performance between Lycee de Mballa II and Lycee d'Application in Yaounde: An error analysis approach. Master's dissertation, The University of Yaounde I. 


\section{Macrothink}

International Journal of English Language Education ISSN 2325-0887 2013, Vol. 1, No. 1

Ntankeu, M. (1989). The performance of students of G. S. S. Sa'a learning English: A study in grammatical ability. Master's dissertation, The University of Yaounde I.

Parrot, M. (2000). Grammar for English Language Teachers. Cambridge: Cambridge University Press.

Saville-Troike, M. (2006). Introducing Second Language Acquisition. Cambridge: Cambridge University Press.

Webelhuth, G. (1992). Principle and Parameters of Syntactic Saturation. Oxford: Oxford University Press.

\section{Copyright Disclaimer}

Copyright reserved by the author(s).

This article is an open-access article distributed under the terms and conditions of the Creative Commons Attribution license (http://creativecommons.org/licenses/by/3.0/). 